\title{
Regimento proueytoso e Modus curandi: edição dos textos
}

\author{
Regimento proueytoso and \\ Modus curandi: edition of the texts
}

\author{
Maria Carlota Rosa \\ Professora do Programa de Pós-graduação em Lingüística e do Departamento de \\ Lingüística e Filologia da Faculdade de Letras da Universidade Federal do Rio de Janeiro \\ Cidade Universitária - Ilha do Fundão \\ 21941-590 Rio de Janeiro - RJ - Brasil \\ carlota@ufrj.br \\ Diana Maul de Carvalho \\ Professora Adjunta, Faculdade de Medicina/UFRJ \\ Rua Mario Portela, 161/1001 bl. A \\ 22241-000 - Rio de Janeiro - RJ - Brasil \\ dianamaul@hotmail.com \\ Dante Martins Teixeira \\ Professor do Programa de Pós-graduação em Zoologia e do \\ Departamento de Vertebrados - Museu Nacional/UFRJ \\ Quinta da Boa Vista $\mathrm{s} / \mathrm{n}$ \\ 20940-040 - Rio de Janeiro - RJ - Brasil
}

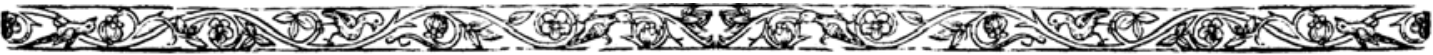

ROSA, M. C.; CARVALHO, D. M.; TEIXEIRA, D. M.: Regimento proueytoso e

Modus curandi: edição dos textos

História, Ciências, Saúde - Manguinhos, v. 12, n. 3, p. 795-800, set.-dez. 2005.

O Regimento proueytoso contra ha pestenença e o Modus curandi cum balsamo são apresentados em edição fac-similar dos exemplares existentes, respectivamente, na Biblioteca Pública de Évora e na Biblioteca Nacional de Portugal. Ambos os fac-símiles receberam edições semidiplomáticas. Segue-se a essa transliteração para caracteres modernos uma tradução; no caso do Regimento, uma tradução intra-línguas, que modernizou o texto; no caso do Modus curandi, o texto latino recebeu tradução para o português atual. No presente texto explicam-se os critérios empregados na edição semidiplomática e, no caso do Regimento, na modernização do texto.

ROSA, M. C.; CARVALHO, D. M.; TEIXEIRA, D. M.: Regimento proueytoso and Modus curandi: edition of the texts.

História, Ciências, Saúde - Manguinhos, v. 12, n. 3, p. 795-800, Sept.-Dec. 2005.

This issue features facsimiles of Regimento proueytoso contra ha pestenença and Modus curandi cum balsamo, based on the original texts housed in the Biblioteca Pública de Evora and the Biblioteca Nacional de Portugal, respectively. Semi-diplomatic editions of both facsimiles - with transliterations into modern characters - have also been provided. These are followed by translations, in the case of Regimento from old to modern Portuguese and in the case of Modus curandi from Latin to modern-day Portuguese. This text explains the criteria used in preparing the semidiplomatic versions and in modernizing the text of Regimento. 


\section{Sobre o Regimento Proueytoso}

\section{[JACOBI, Johannes?] s.d. [1496?]}

Regimento proueytoso contra ha pestenença / Johannes Jacobi [?-1384], trad. de Fr. Luís de Rás [?- ca. 1521] .- Lisboa: Valentino de Morávia.

Descrição: $4^{\circ}(185 \times 120 \mathrm{~mm})$ - [10] fls - assin.: $\mathrm{a}^{6} \mathrm{~b}^{4}$ - car. gót. - tinta preta - linha tirada - 25-26 linhas por mancha - iniciais floreadas ( $28 \times 28 ; 17 \times 17 \mathrm{~mm})-2$ gravuras em madeira: armas portuguesas e adoração à Virgem [a Virgem Maria, a quem a obra é dedicada, com o Menino, envoltos numa aura de fogo. Ao fundo, um castelo. À direita, um homem de joelhos com as mãos postas, que pode representar o Autor; no chão à frente, um livro fechado, alusão à própria obra que terá início. Segundo Anselmo (1991, p. 167), trata-se da primeira gravura impressa em Portugal referente ao culto mariano. A mesma gravura será reproduzida em outra obra impressa por Fernandes, a Ars Virginis Mariae, de Estêvão Cavaleiro, 1516]. Marca d'água: mão enluvada sob flor de cinco pétalas; mão enluvada sob estrela de seis pontas.

\section{Exemplares conhecidos:}

- Biblioteca Pública de Évora, Inc. 210;

- Paço Ducal de Vila Viçosa [Martins, 73].

Não conseguimos confirmar a informação de um colega historiador de que, há cerca de 10 anos, teria consultado um exemplar da obra na Biblioteca Nacional do Rio de Janeiro: não há menção a ela como parte do acervo da instituição quer na edição do Catálogo de incunábulos de 1957, quer na de 1998. Tampouco a informação de Haebler (1903-1917, v. II, p. 100) de que haveria um exemplar da obra na Biblioteca Nacional de Madri foi confirmada pelo Bibliotecário Juan Martin Abad, da Seccion de Incunables y Siglo XVI dessa Biblioteca.

\section{Reedições e estudos:}

RAMINTO, Dom, ? 14-.

Regimento proveitoso contra a pestenença / Dom Raminto. Reedição d'um opusculo rarissimo da Biblioteca d'Evora . - Lisboa : Typ. Rua da Darroca, 1899. - 16 p. ; 29 $\mathrm{cm}$. - Instruções contra a peste no seculo XV.

JORGE, Ricardo, 1858-1939

Regimento proveitoso contra a pestenença: Lisboa, Valentim Fernandes, 1496(?) / Ricardo de Almeida Jorge . - [S.1. : s.n.], 1935 (Lisboa : Tip. Henrique Torres). - 6 p. ; 27 cm

CORREIA, Fernando da Silva, 1893-1966

Regimento proveitoso contra a pestenença / Fernando da Silva Correia . - Lisboa : [s.n., D.L. 1961]. - p. 339-63 ; 23 cm . - Sep. Bol. Clínico Hosp. Civis Lisboa, A. 24 
ROQUE, Mário da Costa, ?-1983

As pestes medievais europeias e o "Regimento proueytoso contra ha pestenença": Lisboa, Valentim Fernandes [1495-1496]: tentativa de interpretação à luz dos conhecimentos pestológicos actuais / Mário da Costa Roque . - Paris : Fundação Calouste Gulbenkian. Centro Cultural Português, 1979. - XVIII, 527, [6] p. : il. ; 26 cm. - (Fontes documentais portuguesas; 12)

SILVA, Marinalva Freire da, 1948-

Edición critica del "Regimento Proueytoso contra ha Pestenença" (¿1496-1500?) [Texto policopiado] / Marinalva Freire da Silva . - Madrid : [s.n.], 1991. - [9], 403 f.; $30 \mathrm{~cm}$. - Tese de doutoramento apresentada ao Departamento de Filología Románica da Fac. de Filosofía e Letras da Univ. Complutense de Madrid

\section{Sobre o Modus curandi}

[ANÔNIMO]. s.d. [1530?]

Modus curãdi cum balsamo atq[ue] aplicatio et eius q[ui]busuis [sic] fracturis et cicatricibus vulneribusq[ue] facile subleuandis .- [Lisboa: Germão Galharde, ca. 1530] .

Descrição: $4^{\circ}(20 \mathrm{~cm})$ - [4] fls - assin.: $\mathrm{a}^{4}$ - car. gót. - tinta preta - linha tirada - 2024 linhas por mancha - capitais fitomórficas $\langle\mathrm{S}\rangle$ e $\langle\mathrm{N}\rangle(50 \times 50 \mathrm{~mm})-$ capitais decoradas de dois tamanhos -2 gravuras em madeira: um doente sendo visitado por uma figura que poderia ser um médico ou um clérigo e a marca do impressor.

\section{Exemplares conhecidos:}

1 Biblioteca Nacional, Portugal, RES. $5561 \mathrm{P}$

\section{Reedições:}

Modus curandi cum balsamo / pref. de José V. de Pina Martins. Ed fac-similada .Lisboa : Biblioteca Nacional, 1988. - 32 p., [10] p. : fac-simil.; $21 \mathrm{~cm}$. - Ed. facsimilada de Lisboa : Germão Galharde, ca. 1530

\section{Sobre a apresentação dos textos}

\section{Edição semidiplomática}

Por conta das dificuldades que a leitura dos fac-símiles podem causar, reproduzem-se esses textos em caracteres tipográficos modernos, neles introduzindo poucos elementos não constantes nos cimélios. Não houve, por conseguinte, a intenção de normalização gráfica, que viesse a excluir as diferentes grafias para uma única palavra, como também não foram inseridos acentos, apóstrofos ou hifens, inexistentes tanto no Regimento como no Modus curandi.

As alterações resumem-se, primeiramente, a apresentar as fronteiras de palavras em acordo com a grafia em uso atualmente. Assim, < pareçevoar> (Regimento, fol.a2 $\left.{ }^{\mathrm{v}}\right)$, ou 
$<$ hocdebetisfacere $>$ (Modus curandi, fol. a2 ${ }^{\mathrm{v}}$ ) foram transliterados como <pareçe voar $>$ e $<$ hoc debetis facere $>$, respectivamente. No caso do texto em português, a fronteira entre palavras divergiu da atual quando a edição refletia um estágio diferente da gramática do português. É o caso de <por tanto>, equivalente a 'por isso', transliterado sempre por duas palavras. Em segundo lugar, tanto no caso do Regimento como no caso do Modus curandi as abreviaturas foram desenvolvidas, assinalado em itálico o que foi inserido.

Em terceiro, não se manteve a distinção, presente em impressos do período, entre o $s$ comprido, $<(>$, e o $s$ redondo, $<\mathrm{s}>$, ambos aqui transliterados como $<\mathrm{s}>$. Ambos estão em distribuição complementar: $<$ ( $>$ está sempre em início ou meio de palavra; $<\mathrm{s}>$, sempre no final. O mesmo se fez para o $r$ redondo, que se seguia $\mathrm{a}\langle\mathrm{p}, \mathrm{b}, \mathrm{d}, \mathrm{h}, \mathrm{o}\rangle$, e $r$ comprido, que se seguia a qualquer outro grafema, inclusive a um $r$ redondo. Contrariamente, porém, mantivemos a distinção entre $\langle\mathrm{v}\rangle$, apenas medial, $\mathrm{e}\langle\mathrm{u}\rangle$, sempre em posição não inicial.

Assinalou-se, entre lambdas deitados, $\langle>$, um provável erro de impressão; entre colchetes, [ ], o que foi introduzido por suposição, uma vez que se apresentava ilegível.

Manteve-se a pontuação original, composta por elenco reduzido de sinais: o caldeirão $\langle\mathbb{I}>$, o coma $<:>$, o cólon $<$. $>$, a vírgula $</>$ e os parênteses $\langle$ ( ) $\rangle$. Os parênteses surgem uma única vez, no último fólio do Regimento, para assinalar uma quebra na sintaxe que introduz um comando direto do narrador ao leitor. O caldeirão assinala grandes unidades de texto, como capítulos, mas, basicamente, que se começou a falar de outra coisa (a título de exemplo, Regimento, fol. a2vi ${ }^{\mathrm{v}}$ Modus curandi, fol. a2). Está sempre imediatamente seguido de maiúscula., mas nunca de capital decorada. O coma indica que algo se segue; não é, porém, muito recorrente nem no texto português nem no latino. Compete com o uso do cólon, de longe o sinal mais empregado na edição do Regimento, que assume tanto as funções de assinalar que algo se lhe segue, como é papel do coma, como que uma unidade de sentido está completa. No texto latino o coma compete com a vírgula (para um estudo sobre a pontuação em impressos portugueses da época, Rosa, 1994). Manteve-se também o uso de maiúsculas e de minúsculas presentes nos cimélios. A maiúscula é preferencialmente empregada em início de oração. Outros usos previstos na época (Rosa, 1994, p. 128) são a indicação de prenome, ou de títulos honoríficos. Duas maiúsculas em seqüência indicam que, no impresso antigo, a primeira era uma capital decorada, sempre seguida de maiúscula.

Atenção, leitor. As obras não apresentam páginas numeradas, mas assinaturas de cadernos. São assinaturas as letras seguidas de algarismos romanos no pé da página ímpar à direita, como <a iij >, por exemplo. Nas antigas casas impressoras, serviam de guia à montagem dos cadernos que compunham um livro. A minúscula $<\mathrm{a}>$ indicava que se tratava do primeiro caderno; os algarismos em romano que se seguiam à letra indicavam a posição da mancha em razão das dobraduras da folha, uma vez que, sendo ambas um in- $4^{\circ}$, cada folha.resultava em oito páginas de impressão. Como apenas se marcava o reto das folhas, e não de todas, optou-se por manter a assinatura, mas nas edições semidiplomáticas que aqui se apresentam, usa-se a composição do caderno como uma paginação, indicando-se no alto da transcrição de cada página a assinatura,. $\mathrm{O}$ verso da página vai indicado por um $\langle\mathrm{v}\rangle$ sobrescrito. Assim, [Fol. a $3^{\mathrm{v}}$ ] indica o verso da terceira página do caderno a. Para cada página foi incluída numeração a cada linha.

Algumas notas chamam a atenção para aspectos lingüísticos dos textos. A maior parte dos comentários está, porém, no glossário. 


\section{A tradução intra ou inter-línguas}

Para o Regimento prouyitoso a edição semidiplomática é acompanhada de uma edição que reproduziu o texto quatrocentista com atualização da ortografia, procurando, porém, respeitar características fonológicas do português da época.

As alterações introduziram fronteiras de palavras em acordo com a grafia atual, hifens entre o verbo e o pronome enclítico, ou em compostos, como <meo-dia $>$. As abreviaturas foram desenvolvidas e alguns recursos gráficos foram introduzidos, como o itálico na indicação dos títulos das obras citadas ao longo do texto, ou aspas nas citações feitas pelo autor. Na edição valentiniana não há acentuação gráfica, que foi introduzida na presente edição.

Eliminou-se a distinção, presente em todos os impressos de Fernandes, entre o $s$ comprido, $<$ ( $>$, e o $s$ redondo, $<$ s $>$; e entre o $r$ redondo e $r$ comprido; entre $<\mathrm{v}>$, sempre inicial, e $<\mathrm{u}>$ consonantal, sempre em posição não inicial.

Assinalou-se, na edição, entre lambdas deitados, $<>$, um provável erro de impressão; entre colchetes, [ ], o que foi introduzido por suposição, uma vez que se apresentava ilegível.

Eliminaram-se os encontros vocálicos resultantes de queda de consoantes, em especial de /d/, /l/ e /n/ que, ao final do século $X V$, permaneciam apenas na grafia, como $<$ maa $>$, $<$ boõ $>$, $<$ pouoo $>$ aqui, respectivamente, $<$ má $>$, $<$ bom $>$ e $<$ povo $>$. Como os ditongos $<$ ae $>$ e $<$ ai $>$ já se confundem nessa fase, optou-se pela grafia $<$ ai $>$. No entanto manteve-se $<$ meo $>$, em lugar da forma atual $<$ meio $>$, por exemplo, uma vez que o iode que desfaz os hiatos $e-a$ e $e-o$ começaria a surgir mais tarde, já no século XVI. A distinção entre <om>, $<$ am $>$ e $<$ ão $>$ já se tornara uma distinção gráfica, cuja pronúncia soaria como o atual $<$ ão $>$; daí a presente edição regularizar as três formas em <ão $>$, como <coração $>$ (em lugar de < coraçam $>$ ou $<$ coraçom $>$ ).

No que respeita ao sistema consonantal, mantivemos $<$ ç $>$ inicial em vocábulos como $<$ çarrados $>$ ou $<$ çumo $>$, uma vez que $<$ ç $>$ representava uma predorsodental surda que não se confundia com a ápico-alveolar surda, realizada graficamente como $<$ s $>$ ou $<$ ss $>$. Diante de $<\mathrm{e}>$ ou $<\mathrm{i}>$, havia alternância entre $<\mathrm{c}>\mathrm{e}<\mathrm{c}>$ para a representação da predorsodental surda; optou-se aqui, nestes casos, pela grafia $<\mathrm{c}\rangle$.

Alteou-se a pontuação original. Como a pontuação não equivale àquela empregada no português atual, procuramos pontuar em acordo com a interpretação que extraímos de nossa leitura do original valentiniano.

Também não se manteve o uso de maiúsculas de Fernandes, preferencialmente empregadas em início de oração, na indicação de prenomes, ou de títulos honoríficos.

Para o Modus curandi apresenta-se uma tradução para o português atual. 


\section{REFERÊNCIAS BIBLIOGRÁFICAS}

Academia das Ciências de Lisboa

1941

Ali, Manoel Said

1971

Anselmo, Artur

1981

Anselmo, Artur 1991

Biblioteca Nacional 1957

Biblioteca Nacional 1998

Cid, Isabel 1988

Haebler, Conrad 1903-1917

Martins, José V.

de Pina (org.)

1989

Rosa, Maria Carlota 1994

Silva Neto, Serafim da 1979

Teyssier, Paul 1984
Bibliografia geral portuguesa.

Vol. I: Século XV. Lisboa: Imprensa Nacional

Gramática histórica da língua portuguesa. [1931] Rio de Janeiro: Acadêmica/Melhoramentos.

Origens da imprensa em Portugal.

Lisboa: Imprensa Nacional/Casa da Moeda.

História da edição em Portugal. Vol. I: Das origens até 1536.

Porto: Lello \& Irmãos.

Catálogo de incunábulos da Biblioteca Nacional do Rio de Janeiro. Rio de Janeiro: Ministério da Educação e Cultura.

Catálogo de incunábulos da Biblioteca Nacional. 2. ed. rev. e aum. Rio de Janeiro: Fundação Biblioteca Nacional.

Incunábulos da Biblioteca Pública e Arquivo Distrital de Évora.

Catálogo abreviado. Évora: Biblioteca Pública e Arquivo Distrital de Évora.

Bibliografía ibérica del siglo XV. Enumeración de todos los libros impresos en España y Portugal hasta el año con notas críticas. Leipzig \& La Haya: Karl W. Hiesemann \& Martinus Nijhoff.

Um grande português: D. Manuel II, 1889-1932, através de alguns livros séculos XV e XVI da sua biblioteca. Lisboa: Fundação da Casa de Bragança.

Pontuação e sintaxe em impressos portugueses renascentistas. Rio de Janeiro: UFRJ. 2 v. Tese de doutoramento apresentada ao Programa de Pós-Graduação em Letras (Lingüística) da Fac. de Letras da Univ. Federal do Rio de Janeiro.

História da língua portuguesa. [1957] Rio de Janeiro: MEC/Presença.

História da língua portuguesa. [1980] Trad. de Celso Cunha. Lisboa: Livr. Sá da Costa. 